\title{
Monitoring of noninvasive ventilation: comparative analysis of different strategies
}

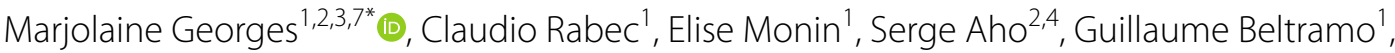 \\ Jean-Paul Janssens ${ }^{5+}$ and Philippe Bonniaud ${ }^{1,2,6+}$
}

\begin{abstract}
Background: Noninvasive ventilation (NIV) represents an effective treatment for chronic respiratory failure. However, empirically determined NIV settings may not achieve optimal ventilatory support. Therefore, the efficacy of NIV should be systematically monitored. The minimal recommended monitoring strategy includes clinical assessment, arterial blood gases ( $\mathrm{ABG}$ ) and nocturnal transcutaneous pulsed oxygen saturation $\left(\mathrm{SpO}_{2}\right)$. Polysomnography is a theoretical gold standard but is not routinely available in many centers. Simple tools such as transcutaneous capnography $\left(\mathrm{TCPCO}_{2}\right)$ or ventilator built-in software provide reliable informations but their role in NIV monitoring has yet to be defined. The aim of our work was to compare the accuracy of different combinations of tests to assess NIV efficacy.

Methods: This retrospective comparative study evaluated the efficacy of NIV in consecutive patients through four strategies $(A, B, C$ and $D)$ using four different tools in various combinations. These tools included morning ABG, nocturnal $\mathrm{SpO}_{2}, \mathrm{TCPCO}_{2}$ and data provided by built-in software via a dedicated module. Strategy A (ABG + nocturnal $\mathrm{SpO}_{2}$ ), B (nocturnal $\mathrm{SpO}_{2}+\mathrm{TCPCO}_{2}$ ) and $\mathrm{C}\left(\mathrm{TCPCO}_{2}+\right.$ builtin software) were compared to strategy $\mathrm{D}$, which combined all four tools (NIV was appropriate if all four tools were normal).
\end{abstract}

Results: NIV was appropriate in only 29 of the 100 included patients. Strategy A considered 53 patients as appropriately ventilated. Strategy B considered 48 patients as appropriately ventilated. Strategy C misclassified only 6 patients with daytime hypercapnia.

Conclusion: Monitoring ABG and nocturnal $\mathrm{SpO}_{2}$ is not enough to assess NIV efficacy. Combining data from ventilator built-in software and $\mathrm{TCPCO}_{2}$ seems to represent the best strategy to detect poor NIV efficacy.

Trial registration Institutional Review Board of the Société de Pneumologie de Langue Française (CEPRO 2016 Georges)

Keywords: Non-invasive ventilation, Monitoring, Transcutaneous capnography, Nocturnal pulse oximetry, Bi-level positive airway pressure, Respiratory failure

\section{Background}

Non-invasive ventilation (NIV) is recognized as an effective treatment of chronic hypercapnic respiratory failure (CHRF) [1]. Due to growing evidence of NIV efficacy in a

\footnotetext{
*Correspondence: marjolaine.georges@chu-dijon.fr

†Jean-Paul Janssens and Philippe Bonniaud contributed equally to this work

${ }^{1}$ Department of Pulmonary Medicine and Intensive Care Unit, University Hospital, Dijon, France

Full list of author information is available at the end of the article
}

broad range of indications as well as increasing availability of high performance and user-friendly home ventilators, the number of patients receiving NIV at home has been regularly increasing over the past 30 years [2-4]. When NIV is initiated to treat CHRF, ventilator settings are empirically determined based on the underlying disease, patient tolerance and diurnal changes in arterial blood gases (ABG) [5]. However, NIV is usually applied during the night. As a result, daytime adjustment of ventilator settings may not achieve optimal nocturnal ventilatory support. This can be explained by sleep-related original author(s) and the source, provide a link to the Creative Commons licence, and indicate if changes were made. The images or other third party material in this article are included in the article's Creative Commons licence, unless indicated otherwise in a credit line to the material. If material is not included in the article's Creative Commons licence and your intended use is not permitted by statutory regulation or exceeds the permitted use, you will need to obtain permission directly from the copyright holder. To view a copy of this licence, visit http://creativecommons.org/licenses/by/4.0/. The Creative Commons Public Domain Dedication waiver (http://creativeco mmons.org/publicdomain/zero/1.0/) applies to the data made available in this article, unless otherwise stated in a credit line to the data. 
changes in breathing. Sleep induces modifications in ventilatory control, respiratory muscle recruitment and upper airway patency, which may all affect ventilatory function especially in patients with CHRF [6]. Moreover, applying intermittent positive pressure may by itself trigger abnormal respiratory events [7]. For instance, reduction of ventilatory drive with or without glottic closure, residual upper airway obstruction and patient-ventilator asynchrony can all compromise the efficacy of NIV [7]. Furthermore, as NIV uses a non-airtight system, unintentional leaks are frequent [8]. Leaks during NIV can interfere with patient-ventilator interaction [9]. These respiratory events are frequent under NIV $[8,10-13]$ and may have an impact on prognosis [14-16].

Therefore, NIV should be systematically monitored. However, optimal modalities for monitoring of long-term ventilated patients remain a matter of debate. Hence, physicians may adopt different approaches to assess NIV performance. Some authors suggest that complete polysomnography (PSG) under NIV should be performed for each patient under NIV to verify its efficacy [7, 17]. This technique is not feasible in many centres on a routine basis. In contrast, the 2010 American Academy Sleep Medicine (AASM) recommendations for best clinical practices state that patients on long term NIV should be assessed regularly with measures of oxygenation and ventilation (i.e.: $\mathrm{ABG}$, nocturnal pulse oximetry, end tidal $\mathrm{CO}_{2}$ or transcutaneous capnography) $[18,19]$. Over the past years, the use of $\mathrm{TcPCO}_{2}$ has been simplified. Home ventilators have built-in software that provide detailed information on relevant ventilator parameters to assess the efficacy of NIV. A step-by-step strategy starting by ABG and nocturnal $\mathrm{SpO}_{2}$ has been proposed by the SomnoNIV group [19]. However, few studies have evaluated these proposed monitoring strategies in clinical practice [20].

This study aimed to compare the accuracy of four different strategies using four easily available assessment tools in different combinations to determine NIV efficacy during elective evaluations of patients on long-term NIV.

\section{Methods}

All patients under long-term home NIV followed by the Pulmonary Department of Dijon University Hospital are hospitalized electively for one night on a regular basis to assess efficacy of their NIV. These admissions are scheduled by the attending specialist every 3 to 12 months: intervals depend on the underlying respiratory disease and its progression rate, prior assessment of NIV efficacy or tolerance and intercurrent medical events.

In this retrospective comparative study, we included consecutive patients treated with long term NIV and hospitalized in our unit for an elective follow-up visit over a 1 year period. Inclusion criteria were: use of a home bi-level pressure support ventilator $\left(\mathrm{VPAP}^{\mathrm{TM}}\right.$, ResMed, North Ryde, Australia) and being in a stable clinical condition for at least 3 months prior to inclusion.

Exclusion criteria included: age below 18 years, oxygen supplementation, use of a ventilator from other manufacturers, mean daily NIV use of less than $4 \mathrm{~h}$ per night, inability to cooperate and change in NIV treatment in the preceding 3 months.

NIV was evaluated with usual ventilator settings and interface. We simultaneously recorded overnight for each patient four monitoring tools: (1) morning ABG measured during spontaneous breathing by puncture of the radial artery during the first hour after disconnection from the ventilator, (2) nocturnal pulsed oxygen saturation $\left(\mathrm{SpO}_{2}\right.$; Nonin model 8500 oximeter, Nonin Medical, Plymouth, MN, USA), (3) transcutaneous capnography $\left(\mathrm{TcPCO}_{2}: \mathrm{Tosca}^{\circledR}\right.$, Radiometer, Copenhagen, Denmark) and (4) data from a simplified monitoring module coupled to their portable ventilator (Reslink ${ }^{\mathrm{TM}}$, ResMed). Data from the ventilator software were collected on a Smart Media card (Scandisk, Milpita, CA, USA) then downloaded with Rescan ${ }^{\text {TM }}$ software (ResMed, North Ryde, Australia). The software provided an accurate estimation of non-intentional air leaks (i.e. leaks exceeding what was expected from the exhalation valve of the interface used) [8]. The additional connection of a pulse oximeter allowed simultaneous recording of nocturnal $\mathrm{SpO}_{2}$.

Thresholds used to interpret results of the four monitoring tools were the following: (1) ABG: $\mathrm{PaCO}_{2} \geq 45 \mathrm{mmHg}$; (2) nocturnal $\mathrm{SpO}_{2}$ : time spent with $\mathrm{SpO}_{2}<90 \%$ for $\geq 30 \%$ of the total recording time [21]; (3) transcutaneous capnography: mean $\mathrm{TcPCO}_{2} \geq 50 \mathrm{mmHg}$ $[22,23]$ and (4) data from built-in ventilator software: leaks ( $>24 \mathrm{l} / \mathrm{min}$ for $>20 \%$ of total recording time), continuous desaturation $\left(\mathrm{SpO}_{2}<90 \%\right.$ for $>30 \%$ of the recording) and cumulated desaturation dips ( $>3 \%$ during $>10 \%$ of the trace) [8].

We evaluated the efficacy of NIV through four strategies (A, B, C and D) using the results of four different tools, in different combinations: strategy $A$ combined ABG and nocturnal $\mathrm{SpO}_{2}$, the minimal recommended monitoring combination [19]; strategy $B$ combined nocturnal $\mathrm{SpO}_{2}$ and $\mathrm{TcPCO}_{2}$ : since transcutaneous capnography provides $\mathrm{SpO}_{2}$ and $\mathrm{TcPCO}_{2}$ simultaneously, both parameters could be analyzed concurrently; strategy $C$ combined $\mathrm{TCPCO}_{2}$ and data from built-in ventilator software and strategy $D$ associated all the available tools (i.e. ABG, nocturnal $\mathrm{SpO}_{2}, \mathrm{TcPCO}_{2}$ and data from ventilator software). Strategy $D$ is used to classify patients as appropriately ventilated or not. If none of the above-mentioned criteria were fulfilled, NIV was considered effective. 
The St. Mary's Hospital questionnaire was completed in the morning after the overnight assessment to evaluate subjective sleep quality on a 12 point scale [24]. Another questionnaire assessed the self-perceived quality of ventilation using an eight-item visual analogic scale (10 points per item) covering three domains: patient-ventilator synchronisation, efficacy and leaks [25]. Higher values indicated better treatment comfort, with a maximum score of 80 .

The study was approved by the Institutional Review Board of the Société de Pneumologie de Langue Française.

\section{Statistical analysis}

Statistical analyses were performed using SigmaPlot 13 software (Systat Software, San Jose, CA, USA). The normality of the distribution of the variables analysed was assessed using the Kolmogorov-Smirnov test. As most data were not normally distributed, we reported results as median and quartiles and used non-parametric tests. We used the Mann Whitney's U test to compare "appropriately" and "inappropriately" ventilated patients for continuous variables. Categorial variables (gender, interfaces) were compared using a $\chi^{2}$ test. For comparisons between three or more groups (classification of patients according to the aetiology of chronic respiratory failure), we used the Kruskal-Wallis test; subsequent paired comparisons were made using a post-hoc Dunn's analysis. Statistical significance was set at $\mathrm{p}<0.05$ or $\mathrm{p}<1-(1-\alpha)^{1 / \mathrm{k}}$ for multiple comparisons where $\alpha=0.05$ and $\mathrm{k}$ denotes the number of comparisons.

The agreement between different methods of NIV monitoring and the strategy $D$ was evaluated with Cohen's kappa coefficient [26].

We used receiver operating characteristic (ROC) curves to evaluate the performance of nocturnal $\mathrm{SpO}_{2}$ and $A B G$ to identify patients classified as adequately ventilated according to strategy $D$. We considered agreement to be sufficient if the lower bound of $95 \%$ confidence interval for the area under the ROC curve was $>0.7$. ROC curve analyses were also used to determine the most suitable threshold values of mean nocturnal $\mathrm{SpO}_{2}$ and morning $\mathrm{PaCO}_{2}$ for assessing NIV efficacy.

\section{Results}

One hundred and thirty-four patients were screened. Two subjects were excluded due to corruption of raw data from the ventilator software. Thirty-two patients under oxygen therapy were also excluded from further analyses. These subjects suffered more often from obstructive lung diseases (OLD) and presented more severe diurnal and nocturnal hypercapnia $(\mathrm{p}<0.001)$.

\section{Study population}

The remaining 100 patients were treated with NIV for OLD $(n=25)$, chest wall diseases $(C W D, n=29)$ and neuromuscular diseases (NMD, $n=46$ ) according to the Eurovent diagnostic groups [2] (Table 1). Demographic characteristics, $\mathrm{ABG}, \mathrm{TcPCO}_{2}$ and ventilator settings are summarized in Table 2. As expected, NMD patients were younger, had a lower BMI and required lower levels of pressure support to reach more effective control of diurnal and nocturnal hypercapnia. Nasal masks were used more frequently in this group than in OLD or CWD subjects $(\mathrm{p}<0.05)$.

\section{Assessment of NIV efficacy}

$\mathrm{TcPCO}_{2}$ revealed significant nocturnal hypoventilation in $27 \%$ of the patients. Among them, $6 \%$ had normal ABG and $12 \%$ had normal nocturnal $\mathrm{SpO}_{2}$. Data from built-in ventilator software were abnormal in $57 \%$ of the patients. Leaks represented the most common abnormality (28\%).

Table 3 compares the performances of different strategies. NIV was appropriate in only $29 \%$ of patients. No significant differences were found regarding ventilator settings or interfaces between appropriately and inappropriately ventilated patients. NIV compliance did not differ significantly between appropriately and inappropriately ventilated patients $(8.5$ [6.9-10] vs. 7.5 [6.1-9.9] hours per night, respectively).

With strategy A, 53\% of patients were considered appropriately ventilated. Among $48 \%$ of patients with normal results using strategy $B$, data from built-in ventilator software identified major leaks in $18 \%$ and significant drops in $\mathrm{SpO}_{2}$ associated with decreases in flow despite effective ventilator pressure in $10 \%$ of patients.

Table 1 Characteristics of the studied population: indications for noninvasive ventilation according to Eurovent categories

\begin{tabular}{ll}
\hline Aetiologic group & Subjects \\
\hline Obstructive lung diseases (OLD) & 25 \\
Chronic obstructive pulmonary disease & 12 \\
Overlap syndrome & 10 \\
Other & 3 \\
Chest wall diseases (CWD) & 29 \\
Obesity hypoventilation syndrome & 21 \\
Tuberculosis sequelae & 3 \\
Kyphoscoliosis & 5 \\
Neuromuscular diseases (NMD) & 46 \\
Myopathy & 25 \\
Amyotrophic lateral sclerosis & 13 \\
Neuropathy & 8 \\
\hline
\end{tabular}

Data are presented as number of subjects 
Table 2 Characteristics of the studied population: demographic data, diurnal and nocturnal gas exchanges and ventilator settings

\begin{tabular}{|c|c|c|c|c|}
\hline Variables & OLD & CWD & NMD & Global population \\
\hline Effective & 25 & 29 & 46 & 100 \\
\hline \multicolumn{5}{|l|}{ Anthropometric data } \\
\hline Age (years) & $70[61-77]$ & $71[60-75]$ & $50[22-62]^{* \AA}$ & $62[47-71]$ \\
\hline Gender (male/female) & $16 / 9$ & $12 / 17$ & $31 / 15$ & $59 / 41$ \\
\hline $\mathrm{BMI}\left(\mathrm{kg} / \mathrm{m}^{2}\right)$ & $39[32.2-41.5]$ & $40[27.2-47.7]$ & $22[18.4-30.5]^{*}$ & $31.0[21.6-40.4]$ \\
\hline \multicolumn{5}{|l|}{ Daytime arterial blood gases } \\
\hline Daytime $\mathrm{PaO}_{2}(\mathrm{mmHg})$ & $66.5[61.1-79.3]$ & $65[60.7-73]$ & $78[71-93]^{* \AA}$ & $71.3[62.4-84]$ \\
\hline Daytime $\mathrm{PaCO}_{2}(\mathrm{mmHg})$ & $45[41.9-49]$ & $42[39.3-47.8]$ & $41[38.5-44.2]^{*}$ & $41.9[39.4-47]$ \\
\hline \multicolumn{5}{|c|}{ Nocturnal transcutaneous capnography } \\
\hline Median $\mathrm{SpO}_{2}(\%)$ & 90 [89-92.4] & $92[89.8-93.3]$ & $95[93.8-96]^{*}$ & 93 [90-95] \\
\hline Median $\mathrm{TcPCO}_{2}(\mathrm{mmHg})$ & $49[44.2-53.2]$ & $48[43-52.4]$ & $43[40-47.3]^{* \curvearrowleft}$ & $45.8[41.9-50.1]$ \\
\hline Maximal $\mathrm{TcPCO}_{2}(\mathrm{mmHg})$ & $55[49.5-64]$ & $56[52.5-59]$ & $48[44-53.5]^{*}$ & $52[46-57]$ \\
\hline $\begin{array}{l}\text { Recording time spent with } \\
\mathrm{TCPCO}_{2}>50 \mathrm{mmHg}\end{array}$ & $58[1.96-89.9]$ & $28[3.3-81.5]$ & $0[0-28.2]^{*}$ & $6.7[0-72.1]$ \\
\hline \multicolumn{5}{|l|}{ Ventilator settings } \\
\hline Inspiratory pressure $\left(\mathrm{cmH}_{2} \mathrm{O}\right)$ & 19 [18-21] & 18 [16-19] & $16[14-17]^{* ף}$ & $17.5[16-19]$ \\
\hline Expiratory pressure $\left(\mathrm{cmH}_{2} \mathrm{O}\right)$ & $8[6-9]$ & $9[5-10]$ & $6[4-8]^{* \Uparrow}$ & $6[4-10]$ \\
\hline Interface: nasal/oronasal mask & $12 / 13$ & $13 / 16$ & $28 / 18^{* \Uparrow}$ & $53 / 47$ \\
\hline Compliance (h/day) & $8.5[7.5-10]$ & $7.2[5.8-9.7]$ & $8[6-9.4]$ & $7.9[6.1-9]$ \\
\hline
\end{tabular}

Data are presented as median [first and third quartiles] or number of subjects

$B M I$ body mass index, CWD chest wall diseases, NIV noninvasive ventilation, NMD neuromuscular diseases, OLD obstructive lung diseases, $\mathrm{PaCO}_{2}$ arterial carbon dioxide partial pressure, $\mathrm{PaO}_{2}$ arterial dioxygen partial pressure $\mathrm{SpO}_{2}$ transcutaneous pulsed oxygen saturation, $\mathrm{TCPCO}_{2}$ transcutaneous carbon dioxide partial pressure * $p<0.05$ for comparisons to OLD group

" $p<0.05$ for comparisons to CWD group (Kruskall-Wallis test then Dunn's post-hoc analysis or $x^{2}$ )

Table 3 Proportion of patients considered as appropriately ventilated according to tests used alone or in various strategies

\begin{tabular}{|c|c|c|}
\hline Evaluation criteria & $\begin{array}{l}\text { Patients fulfilling criteria for appropriate ventilation } \\
\text { according to tests performed alone or in combination }\end{array}$ & Cohen's к coefficient \\
\hline \multicolumn{3}{|l|}{ Assessment tools used alone } \\
\hline Data from Bbuilt-in ventilator software polygraphy & $43(43 \%)$ & $0.685[0.545-0.825]$ \\
\hline $\mathrm{TCPCO}_{2}$ & $73(73 \%)$ & $0.332[0.201-0.465]$ \\
\hline \multicolumn{3}{|l|}{ Assessment tools used in combination } \\
\hline $\mathrm{ABG}+$ nocturnal $\mathrm{SpO}_{2}($ strategy $A)$ & $53(53 \%)$ & $0.557[0.406-0.707]$ \\
\hline Nocturnal $\mathrm{SpO}_{2}+\mathrm{TCPCO}_{2}($ strategy $B)$ & $48(48 \%)$ & $0.601[0.436-0.755]$ \\
\hline $\begin{array}{l}\text { Data from Bbuilt-in ventilator software polygra- } \\
\text { phy }+\mathrm{TCPCO}_{2}(\text { strategy } C)\end{array}$ & $35(35 \%)$ & $0.943[0.876-1]$ \\
\hline $\begin{array}{l}\mathrm{ABG}+\text { nocturnal } \mathrm{SpO}_{2}+\text { ventilator softwareBuilt-in } \\
\left.\text { polygraphy }+\mathrm{TCPCO}_{2} \text { (strategy } D\right)\end{array}$ & $29(29 \%)$ & \\
\hline
\end{tabular}

Data are presented as $\mathrm{n}(\%)$

Abnormal arterial blood gases defined as: $\mathrm{PaCO}_{2} \geq 45 \mathrm{mmHg}$

Abnormal nocturnal $\mathrm{SpO}_{2}$ defined as: time spent with $\mathrm{SpO}_{2}<90 \%$ for $\geq 30 \%$ of total recording time [21]

Abnormal nocturnal TcPCO 2 defined as: mean $\mathrm{TcPCO}_{2} \geq 50 \mathrm{mmHg}[22,23]$

Abnormal data from built-in ventilator software polygraphy defined as abnormal if: $1 /$ leaks ( $>24 \mathrm{l} / \mathrm{min}$ for $>20 \%$ of total recording time); $2 /$ continuous desaturation $\left(\mathrm{SpO}_{2}<90 \%\right.$ for $>30 \%$ of recording) or $3 /$ cumulated desaturations ( $>3 \%$ during $>10 \%$ of recording) [8]

$A B G$ arterial blood gases; $\mathrm{SpO}_{2}$ transcutaneous pulsed oxygen saturation, $T C P C \mathrm{O}_{2}$ transcutaneous carbon dioxide partial pressure

a The capacity of different methods of NIV monitoring was evaluated with Cohen's $\kappa$ coefficient in comparison to strategy $D$ 
When using strategy $C$, NIV was considered appropriate in $35 \%$ of patients. Among them, only $6 \%$ had abnormal ABG and were misclassified. Strategy $C$ performed better than strategies $A$ or $B$ for classifying appropriately vs. inappropriately ventilated patients (Cohen's kappa coefficient, $\mathrm{K}$ for strategy $A$ vs. $D: 0.56$ [0.41-0.71]; strategy $B$ vs. $D: 0.601$ [0.436-0.755]; strategy $C$ vs. $D: 0.94[0.86-1])$.

Optimal threshold values for $\mathrm{PaCO}_{2}$ and $\mathrm{SpO}_{2}$ for identifying suboptimal NIV according to strategy $D$

Table 4 presents ROC curve analysis of optimal threshold value of $\mathrm{ABG}$ and nocturnal $\mathrm{SpO}_{2}$ for identifying appropriately ventilated patients (defined by strategy $D$ ).
A morning $\mathrm{PaCO}_{2}$ value of $42 \mathrm{mmHg}$ was the best threshold for identifying appropriate NIV (Fig. 1a): 69\% of the patients were correctly classified using this value.

The best threshold for time spent with $\mathrm{SpO}_{2}$ below 90\% was $5 \%$ (Fig. 1b): $63 \%$ of the patients were correctly classified using this value. Higher values for time spent with $\mathrm{SpO}_{2}$ below $90 \%$ had a lower sensitivity with a similar specificity.

\section{Subjective assessment of quality of sleep and comfort of ventilation}

Perceive quality of sleep (Fig. 2a) and comfort of ventilation (Fig. 2b) did not differ significantly between appropriately and inappropriately ventilated patients.

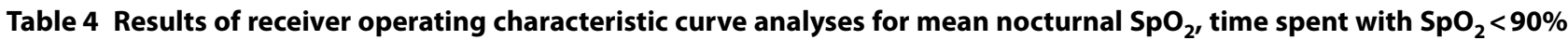
and morning $\mathrm{PaCO}_{2}$ for the detection of inappropriate NIV (according to strategy $D$ )

\begin{tabular}{|c|c|c|c|c|c|}
\hline & Threshold & Sensitivity (\%) & Specificity (\%) & $\begin{array}{l}\text { Positive likelihood } \\
\text { ratio }\end{array}$ & $\begin{array}{l}\text { Negative } \\
\text { likelihood } \\
\text { ratio }\end{array}$ \\
\hline \multirow[t]{5}{*}{ Mean nocturnal $\mathrm{SpO}_{2}(\%)$} & 88 & 7.1 & 100 & 1.08 & 1 \\
\hline & 90 & 32.4 & 100 & 4.38 & 0.69 \\
\hline & 92 & 45.9 & 91.7 & 5.51 & 0.59 \\
\hline & 94 & 71.6 & 70.8 & 2.46 & 0.40 \\
\hline & 96 & 90.5 & 29.2 & 1.28 & 0.32 \\
\hline \multirow{3}{*}{$\begin{array}{l}\text { Time spent with } \mathrm{SpO}_{2}<90 \% \text { (\% of } \\
\text { total recording time) }\end{array}$} & 5 & 63.5 & 95.8 & 15.24 & 0.38 \\
\hline & 20 & 43.2 & 95.8 & 10.38 & 0.59 \\
\hline & 30 & 43.2 & 100 & & 0.57 \\
\hline \multirow[t]{3}{*}{ Morning $\mathrm{PaCO}_{2}(\mathrm{mmHg})$} & 42 & 69.9 & 90.9 & 7.68 & 0.33 \\
\hline & 45 & 50.7 & 95.4 & 14.16 & 0.37 \\
\hline & 48 & 36.2 & 100 & & 0.64 \\
\hline
\end{tabular}

$\mathrm{PaCO}_{2}$ arterial carbon dioxide partial pressure, $\mathrm{SpO}_{2}$ transcutaneous pulsed oxygen saturation

\section{a}

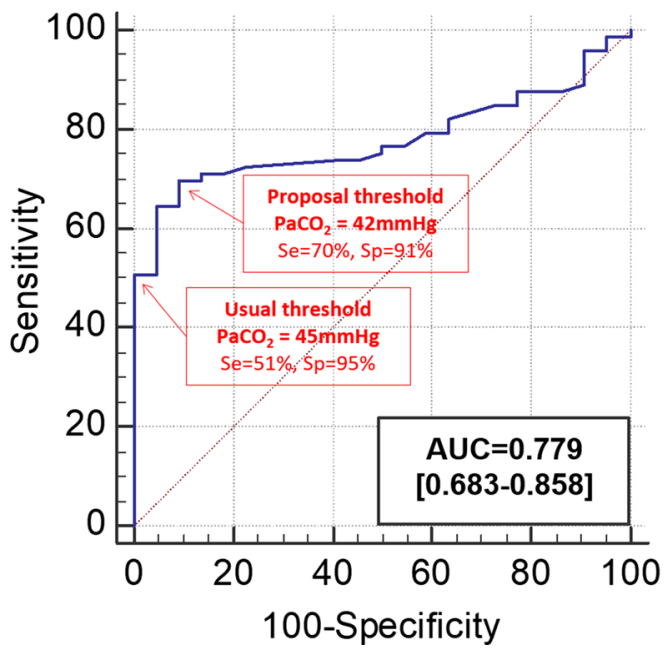

b time spent with $\mathrm{SpO}_{2}$ below $90 \%$

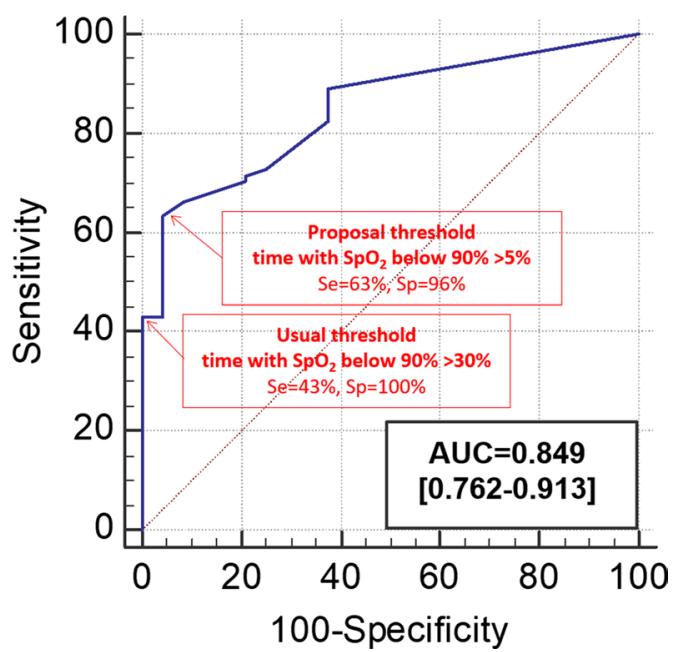

Fig. 1 ROC curve of morning $\mathrm{PaCO}_{2}(\mathbf{a})$ and time spent with $\mathrm{SpO}_{2}$ below $90 \%$ (b) predicting NIV efficacy established by strategy $\mathrm{D}$ 


\section{a}

Time needed to fall asleep (hours)

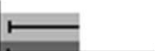

Appropriate NIV ( $\mathrm{n}=29$ )

Difficulty in falling asleep (scale range:1-4)

Early awakening

(yes)

Satisfaction with quality of sleep (scale range: $1-5$ )

\section{Morning sleepiness} (scale range: 1-6)

Quality of sleep (scale range: 1-5)

Duration of sleep (hours)

Number of awakenings

Depth of sleep (scale range: 1-8)

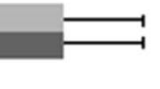

- Inappropriate NIV ( $n=71)$
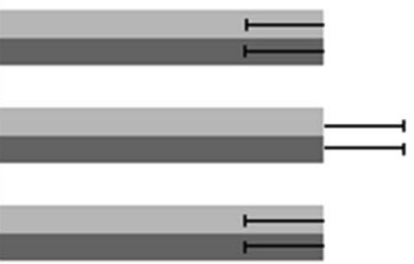

b

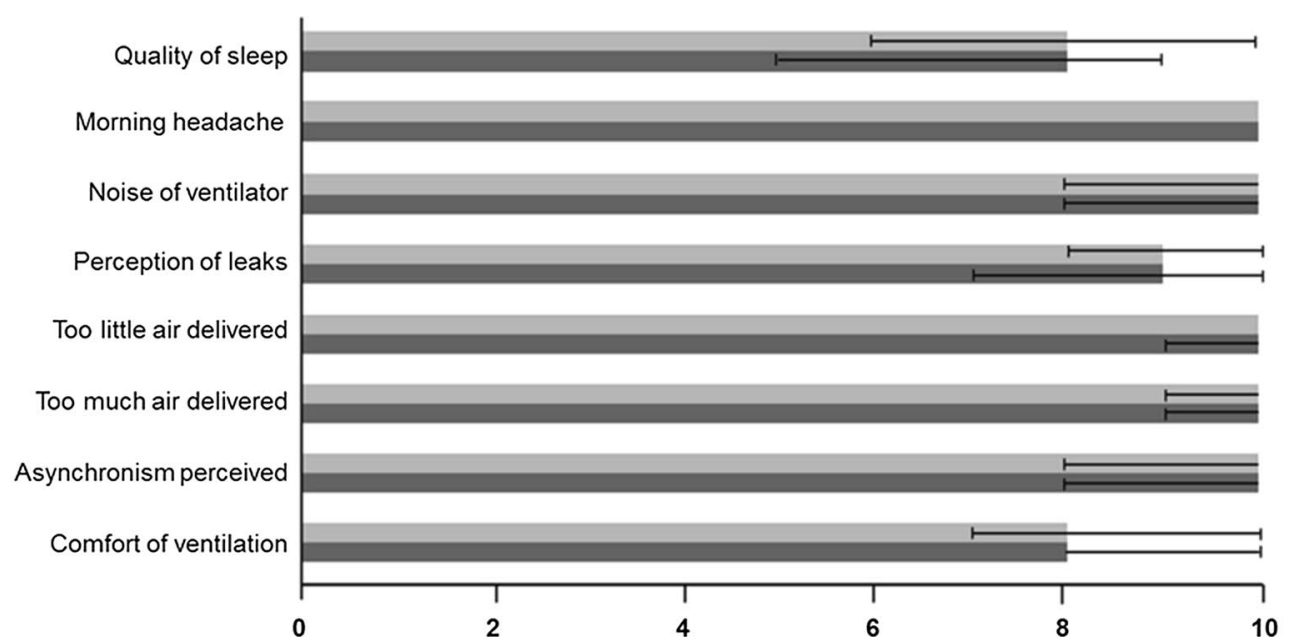

Fig. 2 Patient's rating of quality of sleep and ventilation assessed by St. Mary's Hospital Questionnaire (a) and eight visual analogic scales (b) according to objective efficacy of NIV

Neuromuscular patients reported a worse quality of sleep and increased fragmentation (see Additional file 1 for perceived sleep quality and comfort of ventilation according to Eurovent categories). 


\section{Discussion}

In this real-life study, we compared different strategies to assess the efficacy of NIV. Our results suggest that using a combination of daytime ABG and nocturnal $\mathrm{SpO}_{2}$ (referred to as strategy $A$, proposed by the group of experts [19]) was not sensitive enough to assess NIV efficacy. A significant part of this group had residual nocturnal abnormalities under NIV (hypoventilation, unintentional leaks or abnormal events). In this group, withholding from performing further NIV testing could be deleterious. A combination of $\mathrm{TcPCO}_{2}$ and data from ventilator software, referred to as strategy $C$, was the most accurate non-invasive strategy for assessing NIV efficacy.

Improving NIV efficacy is an important issue in patients with long-term NIV: residual respiratory events under NIV may have a negative impact on patient-related outcomes such as symptoms, health-related quality of life and survival. Nocturnal hypoventilation is associated with a decreased survival rate, especially in neuromuscular diseases [14, 16], as well as adverse neuro-cognitive and cardiovascular consequences in chronic respiratory failure [27]. Leaks above $0.4 \mathrm{l} / \mathrm{s}$ [28] may induce patientventilator asynchrony $[12,29]$, alter quality of sleep [3033] and potentially decrease health-related quality of life. Abnormal respiratory events under NIV (upper airway obstructive events with or without nocturnal desaturations or residual hypoventilation or symptoms) are associated with a decreased survival rate in patients suffering from amyotrophic lateral sclerosis (ALS) [15].

To detect residual nocturnal hypoventilation, we suggest using $\mathrm{TcPCO}_{2}$ instead of morning $\mathrm{ABG}$. In ventilated patients, $\mathrm{PaCO}_{2}$ measured by arterial puncture may not provide an accurate picture of the overnight time course of $\mathrm{PaCO}_{2}[19,22]$. Several studies have shown that continuous $\mathrm{TcPCO}_{2}$ recording is well correlated with arterial measurements in chronic respiratory failure under NIV [10, 34, 35].

Experts propose different thresholds to assess the efficacy of NIV but little evidence substantiates the relevance of these values. Regarding $\mathrm{TcPCO}_{2}$, several thresholds have been suggested to define significant nocturnal hypercapnia: maximal $\mathrm{TcPCO}_{2}>49 \mathrm{mmHg}$ [36, 37]; $\mathrm{TcPCO}_{2}>49 \mathrm{mmHg}$ for $>10 \%$ of recording time [22]; $\mathrm{TcPCO}_{2}>55 \mathrm{mmHg}$ for $\geq 10 \mathrm{~min}$ or an increase in $\mathrm{TcPCO}_{2} \geq 10 \mathrm{mmHg}$ above awake supine value to a

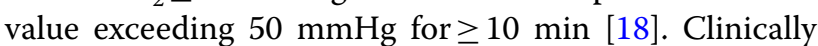
relevant threshold values may differ according to 1 /the method and device used, 2/the etiology of chronic respiratory failure, $3 /$ the goal of $\mathrm{TcPCO}_{2}$ recording (i.e. to decide when NIV should be initiated or to monitor NIV efficacy) and $4 / \mathrm{PCO}_{2}$ levels when NIV is started. For example, prognosis is improved in COPD if NIV effectively reduces $\mathrm{PaCO}_{2}$ by more than 20\% [38]. The thresholds used may also depend on the type of capnograph as bias between arterial and transcutaneous values changes according to the device used [39]. The device used in our study slightly overestimated $\mathrm{PaCO}_{2}$. The maximal bias published with this device was $5.6 \pm 3 \mathrm{mmHg}$ [40]. We therefore considered residual nocturnal hypoventilation as significant when mean $\mathrm{TcPCO}_{2}$ was $\geq 50 \mathrm{mmHg}$ [41].

The clinical contribution of nocturnal transcutaneous capnography can be improved by simultaneously recording $\mathrm{SpO}_{2}$ [19]. Sampling rate and averaging of $\mathrm{SpO}_{2}$ and $\mathrm{TcPCO}_{2}$ recordings are different: $\mathrm{SpO}_{2}$ can detect short desaturations linked to short ventilatory events while $\mathrm{TcPCO}_{2}$ has a longer lag time but is an accurate tool to evaluate overnight trends in ventilation. Hence, both tools are complementary and devices used in clinical practice combine $\mathrm{TcPCO}_{2}$ and $\mathrm{SpO}_{2}$ sensors. However, capnography does not provide information about the underlying pathophysiological mechanisms. Furthermore, in a quarter of patients with normal $\mathrm{TcPCO}_{2}$ and $\mathrm{SpO}_{2}$ (strategy $\mathrm{B}$ ), we found significant leaks or abnormal residual respiratory events (ie, flow reduction or patientventilator asynchronies). Our study confirms the additional contribution of data from ventilator software for the detection of these events. The accuracy of the ResS$\mathrm{can}^{\mathrm{TM}}$ system used to assess leaks has been confirmed in a bench model by our group and others [8, 42].

Our results suggest that using more severe thresholds for $\mathrm{PaCO}_{2}$ and NPO may compensate their lack of sensitivity. For instance, using a $\mathrm{PaCO}_{2}$ threshold value of $42 \mathrm{mmHg}$ could increase the accuracy of ABG for the detection of nocturnal hypoventilation.

Time spent with a $\mathrm{SpO}_{2}$ below $90 \%$ is the most frequently used parameter to interpret nocturnal pulse oximetry, but threshold values vary considerably between authors and aetiologies. In non-ventilated patients suffering from chronic obstructive pulmonary disease (COPD), Levi Valensi et al. [43] documented a shorter survival in patients spending more than $30 \%$ of total sleep time with an $\mathrm{SpO}_{2}$ below $90 \%$. More recently, Gonzalez-Bermejo et al. [14] showed that ALS patients under NIV had a better survival if less than $5 \%$ of NPO time was spent with an $\mathrm{SpO}_{2}<90 \%$. In our study, using a threshold of $5 \%$ increased the accuracy of NPO in detecting residual nocturnal hypoventilation.

An analysis combining the signals provided by $\mathrm{TcPCO}_{2}$ and data from ventilator software may be an interesting option for monitoring NIV, offering a noninvasive global estimation of NIV efficacy without requiring ABG. Moreover, this approach enables unattended assessment both at the hospital and at home without complex logistics. Failure to retrieve data is rare [44] and instrumental drift 
of $\mathrm{TcPCO}_{2}$ is a minor problem when used by an experienced team $[20,39,45,46]$. Interpretation of the results is simple and further analysis of detailed raw data provided by ventilator software can help clarify the underlying mechanism implicated in NIV inefficacy. This may allow optimization of ventilator settings limiting PSG to more complex cases. Unfortunately, use of $\mathrm{TcPCO}_{2}$ is at present still limited by the cost of the devices.

We acknowledge a few limitations to our study. Firstly, we did not perform full PSG under NIV. Even if PSG allows the evaluation of patient-ventilator interactions and characterization of abnormal respiratory events occurring under NIV [7], the impact of these events on morbidity and related therapeutic end points remains speculative [47]. Furthermore, it does not provide an accurate estimation of alveolar ventilation per se, which is the main goal of ventilator assistance. It is also probable that leaks could be underscored by PSG.

Secondly, we excluded 32 patients with nocturnal NIV and oxygen therapy. Supplemental oxygen impacts on $\mathrm{SpO}_{2}$ values and reduces the amplitude of desaturations, decreasing the reliability of NPO to assess NIV efficacy. It must be noted that the majority of excluded patients suffered from chronic obstructive pulmonary disease.

Thirdly, NIV is considered beneficial if used more than 4 h per night (for ALS [48]; for COPD [49]; for obesityhypoventilation syndrome [50]). We also excluded patients using NIV for less than $4 \mathrm{~h}$ per night. Poor compliance to NIV may result from discomfort related to leaks or a low perceived benefit of treatment. This could have underestimated the proportion of inadequately ventilated patients even if leaks represent the most frequent abnormality in our study.

Fourthly, we failed to show an impact of NIV efficacy on sleep quality or patient symptoms. Both scores employed for assessing comfort and quality of sleep have been previously used to assess subjective impact of changes in ventilator modes (volume-targeted versus conventional bi-level pressure support) [25]. Our results suggest that subjective assessment does not suffice for the detection of inappropriate ventilation. The poor correlation between residual respiratory events and patients' perception has been previously reported $[9,10]$. Finally, the impact of NIV efficacy on survival could not be assessed due to the heterogeneity of our population consisting of subgroups (OLD, CWD, NMD) with different prognoses. Further investigations are needed to identify which of the selected tools included significantly impacts on patient-related outcomes such as symptoms, health-related quality of life or survival.

In summary, this study shows that combining morning $\mathrm{ABG}$ and nocturnal $\mathrm{SpO}_{2}$ is not sufficient to accurately assess NIV efficacy. An alternative strategy combining data from ventilator software and $\mathrm{TcPCO}_{2}$ performed better for detecting inappropriate NIV without requiring ABG. Models of care for chronically ill patients living at home are evolving with telemonitoring. $\mathrm{TcPCO}_{2}$ and ventilator software data are increasingly available at home. Moreover, their easy interpretation makes it feasible in real life and in a variety of clinical settings. This combination may be very useful in future strategies for long-term NIV monitoring.

\section{Supplementary Information}

The online version contains supplementary material available at https://doi. org/10.1186/s12931-020-01586-8.

Additional file 1. Patient's rating quality of sleep and ventilation assessed by St. Mary's Hospital Questionnaire and eight visual analogic scales according to aetiological groups and objective efficacy of NIV.

\section{Abbreviations}

ALS: Amyotrophic lateral sclerosis; ABG: Arterial blood gases; BMI: Body mass index; CHRF: Chronic hypercapnic respiratory failure; COPD: Chronic obstructive pulmonary disease; CWD: Chest wall diseases; NIV: Noninvasive ventilation; NMD: Neuromuscular disease; OLD: Obstructive lung diseases; $\mathrm{PaO}_{2}$ : Arterial dioxygen partial pressure; $\mathrm{PaCO}_{2}$ : Arterial carbon dioxide partial pressure; PSG: Polysomnography; $\mathrm{SpO}_{2}$ : Transcutaneous pulsed oxygen saturation; $\mathrm{TCPCO}_{2}$ : Transcutaneous carbon dioxide partial pressure.

\section{Acknowledgements}

None.

\section{Authors' contributions}

MG and CR designed the study. MG, CR, EM and GB collected data. MG, CR and $S A$ analysed the results. MG took the lead in writing the manuscript. All authors discussed the results and contributed to the final version of the manuscript. CR, PB and JPJ provided critical feedback and helped shape the manuscript and design the figures. All authors read and approved the final manuscript.

\section{Funding}

None.

\section{Availability of supporting data}

The datasets generated and analysed during the current study are available from the corresponding author on reasonable request.

\section{Ethics approval and consent to participate}

The study was approved by the Institutional Review Board of the Société de Pneumologie de Langue Française. Patients received a written information regarding this study and the use of their anonymized data for statistical purposes then they give their oral consent.

\section{Consent for publication}

No details relating to an individual person in the manuscript.

\section{Competing interests}

All the authors declare no competing interest.

\section{Author details}

${ }^{1}$ Department of Pulmonary Medicine and Intensive Care Unit, University Hospital, Dijon, France. ${ }^{2}$ University Burgundy Franche-Comté, Dijon, France. ${ }^{3}$ Centre Des Sciences du Goût Et de L'Alimentation, UMR 6265 CNRS 1234 INRA, University Burgundy Franche-Comté, Dijon, France. ${ }^{4}$ Department 
of Epidemiology, Dijon University Hospital, Dijon, France. ${ }^{5}$ Division of Pulmonary Diseases, Geneva University Hospitals, Geneva, Switzerland. ${ }^{6}$ INSERM U1231, University Burgundy Franche-Comté, Dijon, France. ${ }^{7}$ Service de Pneumologie Et Soins Intensifs Respiratoires, Centre Hospitalier Et Universitaire de Dijon, Hôpital François Mitterrand, 14 rue Paul Gaffarel, 21079 Dijon, France.

Received: 27 December 2019 Accepted: 24 November 2020 Published online: 10 December 2020

\section{References}

1. Turkington PM, Elliott MW. Rationale for the use of non-invasive ventilation in chronic ventilatory failure. Thorax. 2000;55(5):417-23.

2. Lloyd-Owen SJ, Donaldson GC, Ambrosino N, Escarabill J, Farre R, Fauroux B, Robert D, Schoenhofer B, Simonds AK, Wedzicha JA. Patterns of home mechanical ventilation use in Europe: results from the Eurovent survey. Eur Respir J. 2005;25(6):1025-31.

3. Rabec C, Gonzalez-Bermejo J, Cuvelier A, Cervantes P, Foret D, Mounier L, Melloni B, Muir JF. Cohort of patients initiated to home ventilation. Observational and prospective study. Rev Mal Respir. 2018;35(1):88-93.

4. Cantero C, Adler D, Pasquina P, Uldry C, Egger B, Prella M, Younossian AB, Soccal PM, Pepin JL, Janssens JP. Long-term noninvasive ventilation in the Geneva Lake Area: indications, prevalence, and modalities. Chest. 2020;158(1):279-91.

5. Elliott MW. Non-invasive ventilation during sleep: time to define new tools in the systematic evaluation of the technique. Thorax. 2011;66(1):82-4.

6. Adler D, Janssens JP. The pathophysiology of respiratory failure: control of breathing, respiratory load, and muscle capacity. Respiration. 2019:97(2):93-104.

7. Gonzalez-Bermejo J, Perrin C, Janssens JP, Pepin JL, Mroue G, Leger P, Langevin B, Rouault S, Rabec C, Rodenstein D, et al. Proposal for a systematic analysis of polygraphy or polysomnography for identifying and scoring abnormal events occurring during non-invasive ventilation. Thorax. 2012;67(6):546-52.

8. Rabec C, Georges M, Kabeya NK, Baudouin N, Massin F, Reybet-Degat $\mathrm{O}$, Camus P. Evaluating noninvasive ventilation using a monitoring system coupled to a ventilator: a bench-to-bedside study. Eur Respir J. 2009;34(4):902-13.

9. Ramsay M. Patient ventilator asynchrony and sleep disruption during non-invasive ventilation. J Thorac Dis. 2018;10(Suppl 1):S80-5.

10. Aarrestad S, Qvarfort M, Kleiven AL, Tollefsen E, Skjonsberg OH, Janssens JP. Sleep related respiratory events during non-invasive ventilation of patients with chronic hypoventilation. Respir Med. 2017;132:210-6.

11. Guo YF, Sforza E, Janssens JP. Respiratory patterns during sleep in obesityhypoventilation patients treated with nocturnal pressure support: a preliminary report. Chest. 2007;131(4):1090-9.

12. Caldarelli V, Borel JC, Khirani S, Ramirez A, Cutrera R, Pepin JL, Fauroux B. Polygraphic respiratory events during sleep with noninvasive ventilation in children: description, prevalence, and clinical consequences. Intensive Care Med. 2013;39(4):739-46.

13. Ramsay M, Mandal S, Suh ES, Steier J, Douiri A, Murphy PB, Polkey M, Simonds A, Hart N. Parasternal electromyography to determine the relationship between patient-ventilator asynchrony and nocturnal gas exchange during home mechanical ventilation set-up. Thorax. 2015;70(10):946-52.

14. Gonzalez-Bermejo J, Morelot-Panzini C, Arnol N, Meininger V, Kraoua S, Salachas F, Similowski T. Prognostic value of efficiently correcting nocturnal desaturations after one month of non-invasive ventilation in amyotrophic lateral sclerosis: a retrospective monocentre observational cohort study. Amyotroph Lateral Scler Frontotemporal Degener. 2013;14(5-6):373-9.

15. Georges M, Attali V, Golmard JL, Morelot-Panzini C, Crevier-Buchman L, Collet JM, Tintignac A, Morawiec E, Trosini-Desert V, Salachas F, et al. Reduced survival in patients with ALS with upper airway obstructive events on non-invasive ventilation. J Neurol Neurosurg Psychiatry. 2016;87(10):1045-50.

16. Ogna A, Nardi J, Prigent H, Quera Salva MA, Chaffaut C, Lamothe L, Chevret S, Annane D, Orlikowski D, Lofaso F. Prognostic value of initial assessment of residual hypoventilation using nocturnal capnography in mechanically ventilated neuromuscular patients: a 5-year follow-up study. Front Med (Lausanne). 2016:3:40.

17. Gonzalez MM, Parreira VF, Rodenstein DO. Non-invasive ventilation and sleep. Sleep Med Rev. 2002;6(1):29-44

18. Berry RB, Chediak A, Brown LK, Finder J, Gozal D, Iber C, Kushida CA, Morgenthaler T, Rowley JA, Davidson-Ward SL, et al. Best clinical practices for the sleep center adjustment of noninvasive positive pressure ventilation (NPPV) in stable chronic alveolar hypoventilation syndromes. J Clin Sleep Med. 2010:6(5):491-509.

19. Janssens JP, Borel JC, Pepin JL, Somno NIVG. Nocturnal monitoring of home non-invasive ventilation: the contribution of simple tools such as pulse oximetry, capnography, built-in ventilator software and autonomic markers of sleep fragmentation. Thorax. 2011;66(5):438-45.

20. Aarrestad S, Qvarfort M, Kleiven AL, Tollefsen E, Skjonsberg OH, Janssens JP. Diagnostic accuracy of simple tools in monitoring patients with chronic hypoventilation treated with non-invasive ventilation; a prospective cross-sectional study. Respir Med. 2018;144:30-5.

21. Levi-Valensi P, Weitzenblum E, Rida Z, Aubry P, Braghiroli A, Donner C, Aprill M, Zielinski J, Wurtemberger G. Sleep-related oxygen desaturation and daytime pulmonary haemodynamics in COPD patients. Eur Respir J. 1992;5(3):301-7.

22. Paiva R, Krivec U, Aubertin G, Cohen E, Clement A, Fauroux B. Carbon dioxide monitoring during long-term noninvasive respiratory support in children. Intensive Care Med. 2009;35(6):1068-74.

23. Simonds AK. Home ventilation. Eur Respir J Suppl. 2003;47:38s-46s.

24. Ellis BW, Johns MW, Lancaster R, Raptopoulos P, Angelopoulos N, Priest RG. The St. Mary's Hospital sleep questionnaire: a study of reliability. Sleep. 1981;4(1):93-7.

25. Janssens JP, Metzger M, Sforza E. Impact of volume targeting on efficacy of bi-level non-invasive ventilation and sleep in obesity-hypoventilation. Respir Med. 2009;103(2):165-72.

26. Landis JR, Koch GG. The measurement of observer agreement for categorical data. Biometrics. 1977;33(1):159-74.

27. Fletcher E, Donner C, Midgren B, Zielinski J, Levi-Valensi P, Braghiroli A, Rida Z, Miller C. Survival in COPD patients with a daytime $\mathrm{PaO} 2$ greater than $60 \mathrm{~mm} \mathrm{Hg}$ with and without nocturnal oxyhemoglobin desaturation. CHEST J. 1992;101(3):649-55.

28. Teschler $\mathrm{H}$. Monitoring of the home mechanical ventilated patient. Eur Respir Monogr. 2001;6:274-80.

29. Carteaux G, Lyazidi A, Cordoba-Izquierdo A, Vignaux L, Jolliet P, Thille AW, Richard JC, Brochard L. Patient-ventilator asynchrony during noninvasive ventilation: a bench and clinical study. Chest. 2012;142(2):367-76.

30. Teschler H, Stampa J, Ragette R, Konietzko N, Berthon-Jones M. Effect of mouth leak on effectiveness of nasal bilevel ventilatory assistance and sleep architecture. Eur Respir J. 1999;14(6):1251-7.

31. Rabec C, Rodenstein D, Leger P, Rouault S, Perrin C, Gonzalez-Bermejo J. Ventilator modes and settings during non-invasive ventilation: effects on respiratory events and implications for their identification. Thorax. $2011 ; 66: 170-8$

32. Meyer TJ, Pressman MR, Benditt J, McCool FD, Millman RP, Natarajan R, Hill NS. Air leaking through the mouth during nocturnal nasal ventilation: effect on sleep quality. Sleep. 1997;20(7):561-9.

33. Pépin J, Borel J, Janssens J, Tamisier R, Levy P. Sleep and NIV: monitoring of the patient under home ventilation. Eur Respir Mon. 2008;41:350-66.

34. Maniscalco M, Zedda A, Faraone S, Carratu P, Sofia M. Evaluation of a transcutaneous carbon dioxide monitor in severe obesity. Intensive Care Med. 2008;34(7):1340-4.

35. Török SS, Leuppi D Jr, Baty F, Tamm M, Chhajed PN. Combined oximetrycutaneous capnography in patients assessed for long-term oxygen therapy. CHEST J. 2008;133(6):1421-5.

36. Ward S, Chatwin M, Heather S, Simonds AK. Randomised controlled trial of non-invasive ventilation (NIV) for nocturnal hypoventilation in neuromuscular and chest wall disease patients with daytime normocapnia. Thorax. 2005:60(12):1019-24.

37. Nardi J, Prigent H, Adala A, Bohic M, Lebargy F, Quera-Salva MA, Orlikowski D, Lofaso F. Nocturnal oximetry and transcutaneous carbon dioxide in home-ventilated neuromuscular patients. Respir Care. 2012;57(9):1425-30.

38. Murphy PB, Rehal S, Arbane G, Bourke S, Calverley PMA, Crook AM, Dowson L, Duffy N, Gibson GJ, Hughes PD, et al. Effect of home noninvasive ventilation with oxygen therapy vs oxygen therapy alone on hospital 
readmission or death after an acute COPD exacerbation: a randomized clinical trial. JAMA. 2017;317(21):2177-86.

39. Aarrestad S, Tollefsen E, Kleiven AL, Qvarfort M, Janssens JP, Skjonsberg $\mathrm{OH}$. Validity of transcutaneous PCO2 in monitoring chronic hypoventilation treated with non-invasive ventilation. Respir Med. 2016;112:112-8.

40. Stein N, Matz H, Schneeweiss A, Eckmann C, Roth-Isigkeit A, Huppe M, Gehring $\mathrm{H}$. An evaluation of a transcutaneous and an end-tidal capnometer for noninvasive monitoring of spontaneously breathing patients. Respir Care. 2006:51(10):1162-6.

41. Simonds AK. Chronic hypoventilation and its management. Eur Respir Rev. 2013;22(129):325-32.

42. Contal O, Vignaux L, Combescure C, Pepin JL, Jolliet P, Janssens JP. Monitoring of noninvasive ventilation by built-in software of home bilevel ventilators: a bench study. Chest. 2012;141(2):469-76.

43. Levi-Valensi P, Aubry P, Rida Z. Nocturnal hypoxemia and long-term oxygen therapy in COPD patients with daytime $\mathrm{PaO} 260-70 \mathrm{mmHg}$. Lung. 1990;168(Suppl):770-5.

44. Bauman KA, Kurili A, Schmidt SL, Rodriguez GM, Chiodo AE, Sitrin RG. Home-based overnight transcutaneous capnography/pulse oximetry for diagnosing nocturnal hypoventilation associated with neuromuscular disorders. Arch Phys Med Rehabil. 2013;94(1):46-52.

45. Felemban O, Leroux K, Aubertin G, Miandy F, Damagnez F, Amorim B, Ramirez A, Fauroux B. Value of gas exchange recording at home in children receiving non-invasive ventilation. Pediatr Pulmonol. 2011;46(8):802-8
46. Georges M, Nguyen-Baranoff D, Griffon L, Foignot C, Bonniaud P, Camus $\mathrm{P}$, Pepin JL, Rabec C. Usefulness of transcutaneous PCO2 to assess nocturnal hypoventilation in restrictive lung disorders. Respirology. 2016;21(7):1300-6.

47. Hannan LM, Rautela L, Berlowitz DJ, McDonald CF, Cori JM, Sheers N, Chao C, O'Donoghue FJ, Howard ME. Randomised controlled trial of polysomnographic titration of noninvasive ventilation. Eur Respir J. 2019;53(5):1802118.

48. Bourke SC, Tomlinson M, Williams TL, Bullock RE, Shaw PJ, Gibson GJ. Effects of non-invasive ventilation on survival and quality of life in patients with amyotrophic lateral sclerosis: a randomised controlled trial. Lancet Neurol. 2006;5(2):140-7.

49. Borel JC, Pepin JL, Pison C, Vesin A, Gonzalez-Bermejo J, Court-Fortune I, Timsit JF. Long-term adherence with non-invasive ventilation improves prognosis in obese COPD patients. Respirology. 2014;19(6):857-65.

50. Mokhlesi B. Obesity hypoventilation syndrome: a state-of-the-art review. Respir Care. 2010;55(10):1347-62 (discussion 1363-1345).

\section{Publisher's Note}

Springer Nature remains neutral with regard to jurisdictional claims in published maps and institutional affiliations.
Ready to submit your research? Choose BMC and benefit from:

- fast, convenient online submission

- thorough peer review by experienced researchers in your field

- rapid publication on acceptance

- support for research data, including large and complex data types

- gold Open Access which fosters wider collaboration and increased citations

- maximum visibility for your research: over $100 \mathrm{M}$ website views per year

At BMC, research is always in progress.

Learn more biomedcentral.com/submissions 